\title{
Modulations in Oscillatory Frequency and Coupling in Globus Pallidus with Increasing Parkinsonian Severity
}

\author{
DAllison T. Connolly, ${ }^{1}$ Alicia L. Jensen, ${ }^{2}$ Edward M. Bello, ${ }^{1}$ Theoden I. Netoff, ${ }^{1}$ Kenneth B. Baker, ${ }^{2}$ \\ Matthew D. Johnson, ${ }^{1,3}$ and Jerrold L. Vitek ${ }^{2}$ \\ ${ }^{1}$ Department of Biomedical Engineering and ${ }^{2}$ Department of Neurology, University of Minnesota, Minneapolis, Minnesota 55455 and ${ }^{3}$ Institute for \\ Translational Neuroscience, University of Minnesota, Minneapolis, Minnesota 55455
}

\begin{abstract}
While beta oscillations often occur within the parkinsonian basal ganglia, how these oscillations emerge from a naive state and change with disease severity is not clear. To address this question, a progressive, nonhuman primate model of Parkinson's disease was developed using staged injections of MPTP. Within each parkinsonian state (naive, mild, moderate, and severe), spontaneous local field potentials were recorded throughout the sensorimotor globus pallidus. In the naive state, beta oscillations $(11-32 \mathrm{~Hz})$ occurred in half of the recordings, indicating spontaneous beta oscillations in globus pallidus are not pathognomonic. Mild and moderate states were characterized by a narrower distribution of beta frequencies that shifted toward the $8-15 \mathrm{~Hz}$ range. Additionally, coupling between the phase of beta and the amplitude of highfrequency oscillations $(256-362 \mathrm{~Hz})$ emerged in the mild state and increased with severity. These findings provide a novel mechanistic framework to understand how progressive loss of dopamine translates into abnormal information processing in the pallidum through alterations in oscillatory activity. The results suggest that rather than the emergence of oscillatory activity in one frequency spectrum or the other, parkinsonian motor signs may relate more to the development of altered coupling across multiple frequency spectrums.
\end{abstract}

Key words: globus pallidus; local field potential; oscillations; Parkinson's disease; phase-amplitude coupling

\section{Introduction}

Spontaneous beta oscillations in the basal ganglia have been implicated in the pathophysiology of parkinsonism (Bergman et al., 1994; Wichmann and DeLong, 2003; Kühn et al., 2005; Brown, 2007; de Solages et al., 2010; Zaidel et al., 2010; Rosa et al., 2011; Shimamoto et al., 2013), and suppression of these oscillations has been shown to correlate with the therapeutic onset of dopamine replacement (Weinberger et al., 2006; Ray et al., 2008; George et al., 2013) and deep brain stimulation (Kühn et al., 2008; Ray et al., 2008; Whitmer et al., 2012) treatment. However, the extent to which such oscillatory activity emerges and varies across parkinsonian severities and subjects remains unresolved.

The oscillatory theory of parkinsonism suggests that spontaneous beta oscillations in the basal ganglia develop with loss of dopaminergic tone (Doyle et al., 2005; Brown, 2007; Hahn and McIntyre, 2010; Holgado et al., 2010) and that the spectral power of these oscillations correlates with the parkinsonian severity (Leblois et al., 2007; Kühn et al., 2009; Devergnas et al., 2014).

\footnotetext{
Received Oct. 6, 2014; revised March 9, 2015; accepted March 12, 2015

Author contributions: A.L.J, K.B.B., and J.L.V. designed research; A.T.C., A.L.J., and M.D.J. performed research; A.T.C., E.M.B., T.I.N., and M.D.J. analyzed data; A.T.C., K.B.B., M.D.J., and J.L.V. wrote the paper.

This material is based upon work supported by the National Institutes of Health under Grant R01-NS058945 and the National Science Foundation Graduate Research Fellowship under Grant 00006595. We thank Partha Mitra (Cold Spring Harbor Laboratory), Abirami Muralidharan, Claudia Hendrix, Filippo Agnesi, and Jacob Neis (University of Minnesota) for their technical assistance.

The authors declare no competing financial interests.

Correspondence should be addressed to Jerrold L. Vitek, Department of Neurology, University of Minnesota, MMC 295, 420 Delaware Street SE, Minneapolis, MN 55455. E-mail: vitek004@umn.edu.

DOI:10.1523/JNEUROSCI.4137-14.2015

Copyright $\odot 2015$ the authors $\quad 0270-6474 / 15 / 356231-10 \$ 15.00 / 0$
}

However, there are several known issues with this theoretical framework to consider. For one, beta oscillations have been observed in the basal ganglia-thalamo-cortical circuit in naive and awake rats (Berke et al., 2004; Leventhal et al., 2012), nonhuman primates (NHP; Murthy and Fetz, 1992; Courtemanche et al., 2003), and humans (Jensen et al., 2005), and these oscillations were modulated by voluntary movements (Sanes and Donoghue, 1993; Murthy and Fetz, 1996). Additionally, the presence of spontaneous beta oscillations in the subthalamic nucleus (STN) region (Priori et al., 2002; Brown et al., 2004; Kühn et al., 2008; Rosa et al., 2011) and globus pallidus (GP; Priori et al., 2002; Silberstein et al., 2003; Brown et al., 2004; Kühn et al., 2008) is not universal. Similar mixed results have been reported in nonhuman primates rendered parkinsonian with the dopaminergic neurotoxin 1-methyl-4-phenyl-1,2,3,6-tetrahydropyridine (MPTP) (Goldberg et al., 2004; Leblois et al., 2007; Devergnas et al., 2014).

More evidence is needed to understand the role, if any, oscillations play in the development of parkinsonian motor signs, whether they correlate with the severity of parkinsonism, and how other features of oscillatory activity such as cross-frequency coupling (Özkurt et al., 2011; de Hemptinne et al., 2013; Shimamoto et al., 2013; Yang et al., 2014) affect information processing through the basal ganglia-thalamo-cortical circuit as parkinsonian motor signs emerge. To address this question, we developed a progressive, nonhuman primate MPTP model of parkinsonism and assessed local field potential (LFP) activity in the sensorimotor GP in each parkinsonian state. We hypothesized that, if beta activity is pathognomonic of parkinsonism, it would emerge in the early stages of MPTP treatment and increase 
as parkinsonian motor signs became progressively more severe with additional MPTP treatments.

\section{Materials and Methods}

\section{Subjects}

Three adult rhesus macaque monkeys (Macaca mulatta)—P1 (female, $5.2 \mathrm{~kg}, 11$ years old), P2 (male, $9.4 \mathrm{~kg}, 12$ years old), and P3 (female, 8.4 $\mathrm{kg}, 23$ years old)-were used in this study. All procedures were performed in compliance with the United States Public Health Service policy on the humane care and use of laboratory animals.

\section{Surgical procedures}

Imaging. Magnetic resonance imaging ( $3 \mathrm{~T}$ or $7 \mathrm{~T}$ ) and computed tomography scans of the head were acquired for each animal. Both datasets were incorporated into a neurosurgical navigation program, Monkey Cicerone (Miocinovic et al., 2007), to aid in the orientation and placement of a cephalic recording chamber (Crist Instrument).

Chamber surgery. Each animal was implanted with a titanium cephalic recording chamber oriented toward the pallidum and a stainless steel head post for head fixation (Elder et al., 2005). Subject P1 was implanted with a $19 \mathrm{~mm}$ chamber in the parasagittal plane (angled posteriorly 42.5 degrees from vertical). Subject P2 was implanted with a $30 \mathrm{~mm}$ chamber (angled 29 degrees from vertical in the coronal plane and anteriorly 29.5 degrees from vertical in the sagittal plane). Subject P3 was implanted with a $19 \mathrm{~mm}$ chamber (angled 24 degrees off vertical in the coronal plane and anteriorly 24.5 degrees from vertical in the sagittal plane).

MPTP injections. Animals were rendered progressively parkinsonian through intracarotid and intramuscular injections of MPTP (0.2-0.6 $\mathrm{mg} / \mathrm{kg}, 1 \mathrm{mg} / \mathrm{ml}$ solution, $\sim 15 \mathrm{~min}$ infusion for intracarotid). The intracarotid injections were unilateral and given repeatedly until reaching a mild, moderate, and severe parkinsonian state as defined below. For each animal, one or more systemic intramuscular injections were required to achieve moderate and/or severe parkinsonism.

\section{Behavioral assessments}

Animals were acclimated to sitting in a primate chair and having their extremities passively manipulated. After a $72 \mathrm{~h}$ quarantine period following MPTP injection, motor behavior was indexed using a modified Unified Parkinson's Disease Rating Scale (mUPDRS), which rated limb rigidity, bradykinesia, akinesia, tremor, and other parkinsonian signs on a scale of 0-3 (Vitek et al., 2012). mUPDRS scores were then measured periodically throughout the recording period to ensure stability of parkinsonian motor signs (mild: $3-13$, moderate: $18-28$, and severe: $32-$ 42). Subscale scores for cardinal parkinsonian motor signs were averaged across the arm and leg contralateral to MPTP lesion and averaged across measurements within each parkinsonian state.

\section{LFP recordings}

A multichannel microdrive system (Alpha EPS; Alpha Omega) was mounted to the recording chamber and two guide tubes were used to puncture the dura mater. Two epoxy-insulated tungsten microelectrodes (impedance 0.8-1.2 $\mathrm{M} \Omega$ measured at $1 \mathrm{kHz}$; FHC) were introduced through the guide tubes and advanced independently at $10 \mu \mathrm{m}$ increments into and through the globus pallidus. Recording data were bandpass filtered into a spike channel $(250 \mathrm{~Hz}-10 \mathrm{kHz})$ and LFP channel $(0.075-390 \mathrm{~Hz})$, which were sampled at $22.5 \mathrm{kHz}$ and $781.3 \mathrm{~Hz}$, respectively. In all cases, the recording chamber was used as the return electrode. Recordings presented here are LFP recordings from trials of spontaneous, resting-state activity $(30-120 \mathrm{~s})$ with the animal awake and sitting in its primate chair.

Neurons within the GP were identified by their firing rates and patterns (Filion and Tremblay, 1991; Boraud et al., 2002) and by crossreferencing the microelectrode positions with Monkey Cicerone. Recordings of single-unit activity in the GP were analyzed during movement about the wrist, elbow, shoulder, hip, knee, and ankle joints to further define the pallidal somatotopy. LFPs were included in the analysis if at least one of the electrodes recorded action potentials from a single cell whose firing rate and pattern were indicative of GPe or GPi neurons, while the second electrode was in or near the pallidum. A total of 676
Table 1. Count of pallidal LFP recordings across subjects and parkinsonian states

\begin{tabular}{lccccc}
\hline & Naive & Mild & Moderate & Severe & Total \\
\hline P1 & 103 & 71 & 39 & 56 & 269 \\
P2 & 118 & 52 & 43 & 40 & 253 \\
P3 & 48 & 34 & 72 & & 154 \\
Total & 269 & 157 & 154 & 96 & 676 \\
\hline
\end{tabular}

paired recordings was made across the three subjects with at least one microelectrode in the sensorimotor GP (Table 1). For most subjects, the largest number of recordings was collected in the naive state as part of an initial mapping of pallidal boundaries and somatotopy.

\section{Data analysis}

Spectral analysis of the LFP recordings was performed off-line in MATLAB (v2012a; The MathWorks) using the Chronux toolbox (Bokil et al., 2010). All recordings were detrended and passed through a moving window line noise subtraction algorithm to remove drifting baseline and continuous noise artifacts, respectively. Each pair of LFPs was then converted to a bipolar recording by subtracting one from the other to remove common far-field signal that may arise from the chamber return electrode.

Spectrograms were calculated using the multitaper method with a $2 \mathrm{~s}$, $20 \%$ overlap moving window, and three tapers, resulting in a $0.5 \mathrm{~Hz}$ frequency resolution. Windows containing movement artifacts were visually identified by large fluctuations in the time series and highamplitude broadband activity in the spectrogram and were removed from further analysis. Remaining windows were assumed to be stationary and were averaged together to calculate the power spectral density (PSD). Outlier PSDs were identified as recording with average power over all frequencies outside of the range mean $\pm 2.7 \mathrm{SDs}$, corresponding to $99.3 \%$ of a Normal distribution.

Each bipolar recording consisted of a unique fall-off that was not necessarily Brownian in nature, as is typical of LFPs (Milstein et al., 2009). A standard significance detection technique using a threshold based on mean and SD over all frequencies $(f)$ would lead to false positives in the low-frequency range and false negatives in the high-frequency range. To correct for this fall-off, each bipolar PSD was fit using leastsquares regression to the model equation

$$
P S D_{\text {model }}=\frac{A}{(C * f+B)^{n}}+D
$$

where $A-D$ and $n$ are constants. The model was inverted to calculate the flattened PSD by

$$
P S D_{\text {flat }}=\frac{P S D_{\text {raw }}}{P S D_{\text {model }}}=\frac{P S D_{\text {raw }}}{\frac{A}{(C * f+B)^{n}}+D}
$$

Within each PSD, beta oscillations were identified as local maxima having amplitude larger than mean \pm 3 SDs of the spectral power between 100 and $390 \mathrm{~Hz}$. Each beta oscillation was treated as andependent sample, even where multiple peaks occurred in the same recording, and the oscillations occurring in the beta band were analyzed. Frequencies in the overall beta band were further segregated into a low $(11-22 \mathrm{~Hz})$ and high $(22-32 \mathrm{~Hz})$ beta band.

\section{Phase-amplitude coupling}

Each recording was zero-phase bandpass filtered (fourth-order Butterworth) into base $\sqrt{2}$ frequency bands from 0.1 to $1.4,1.4$ to 2,2 to $2.8,2.8$ to $4, \ldots, 181-256,256-362$, and $>362 \mathrm{~Hz}$. The amplitude $A(t)$ and phase $\phi(t)$ of each frequency band was calculated by taking the magnitude and angle of the Hilbert transform, respectively (Tort et al., 2010). Previously identified epochs containing movement artifacts were cropped from the phase and amplitude signals. For any given coupling of one band's phase content with another band's amplitude content, the phase signal was discretized into 20 equally spaced bins between 0 and $2 \pi$, and amplitudes that occurred concurrently with a given phase bin were averaged together 
to give a distribution of amplitude values across those phase values $\bar{A}(\phi)$. The distribution of average amplitudes $p$ was normalized over all phase bins $p=\bar{A}(\phi) / \sum_{\phi} \bar{A}(\phi)$, and the entropy of the distribution was calculated as $H=-\sum_{\phi} p \operatorname{In} p$. To calculate statistical significance for a given phase-amplitude pair, the entropy was compared with a distribution of entropies calculated from 1000 surrogates, each created by randomly shifting the phase data in time. The mean $\mu_{H}$ and SD $\sigma_{H}$ of the surrogate distribution were calculated. A modulation index (MI) was then computed based upon normalization to the surrogates, $M I=\left(\mu_{H}-H\right) / \sigma_{H}$. The MI measure was defined between each phase signal band and all amplitude signal bands that had higher frequency content than the phase signal band.

For each recording with significant MI $(\alpha>0.05$ with Bonferroni correction), the phase at which the distribution $p$ was maximum was recorded and used to create a radial histogram for each subject in each state. The electrode pairs used were randomly oriented with respect to the dipole, thus yielding diametrically bimodal circular distributions for those radial histograms with clear azimuths. Thus, an angle-doubling procedure was performed in which each angle was doubled and if $>360^{\circ}$, the doubled angle was deducted by $360^{\circ}$. The resulting angular data were then analyzed using a mean axial vector with direction $(\theta)$ and length $(d)$ defined as follows:

$$
\theta=\tan ^{-1} \frac{\mathfrak{I}(V)}{\mathfrak{R}(V)}, d=\frac{|V|}{n}, \text { where } V=\sum_{i=1}^{n} \cos \left(a_{i}\right)+i \sin \left(a_{i}\right)
$$

and an angular dispersion measure $(r)$ defined $[0,1]$ according to the following:

$$
r=\sqrt{X^{2}+Y^{2}}, \text { where } X=\frac{\sum_{i=1}^{n} \cos \left(a_{i}\right)}{n} \text { and } Y=\frac{\sum_{i=1}^{n} \sin \left(a_{i}\right)}{n}
$$

where $a_{i}$ were the angles after the doubling procedure and $n$ was the total number of significant angles.

\section{Statistics}

Statistical testing was performed using MATLAB and JMP 11 (SAS). Data did not pass the Lilliefors test for Normality or constant variance. Therefore, a nonparametric ANOVA based on ranked data was used to identify significant effects of disease state, subject, and interaction effects. Post hoc comparisons testing for differences in features between disease states were performed using Dunn's all-pairs test for joint ranks with adjusted significance level $\alpha=0.05 / n$ where $n$ is the number of comparisons.

To investigate trends between the occurrence of phase-amplitude coupling (PAC) and disease severity, the MI was calculated for each recording between each of the 18 phase-frequency bands and the amplitudes of bands of higher frequencies. The PAC between phases of higher frequencies with lower amplitudes and with the same frequency of phase and amplitude were excluded from the analysis. The resulting MI was thresholded at a significance level of $\alpha=0.05 / n$, where $n=(18 * 18-18) / 2$ comparisons. The Pearson's $\chi^{2}$ test was used to test if the proportion of recordings with significantly high MI for each phase-amplitude pair changed with parkinsonian severity. A Bonferroni correction was used to adjust for the number of frequency band pairs $n$. The radial histogram results were analyzed for uniformity and significance of the radial mean direction using a $\chi^{2}$ statistic and an Omnibus test for nonuniformity of circular data, respectively $(\alpha=0.05)$.

To investigate finer trends between motor signs and LFPs, the correlation between mUPDRS (overall and cardinal motor sign subscores) and peak frequency was calculated using Spearman's $\rho$. To rule out the influence of alternative parameters on frequencies of beta, the effects of $\mathrm{AP}$ and $\mathrm{ML}$ recording locations were tested using nonparametric linear regression based on ranked data. The correlation between oscillatory frequencies and distance between recording electrodes and between oscillatory frequencies and recording depth were tested using Spearman's $\rho$.

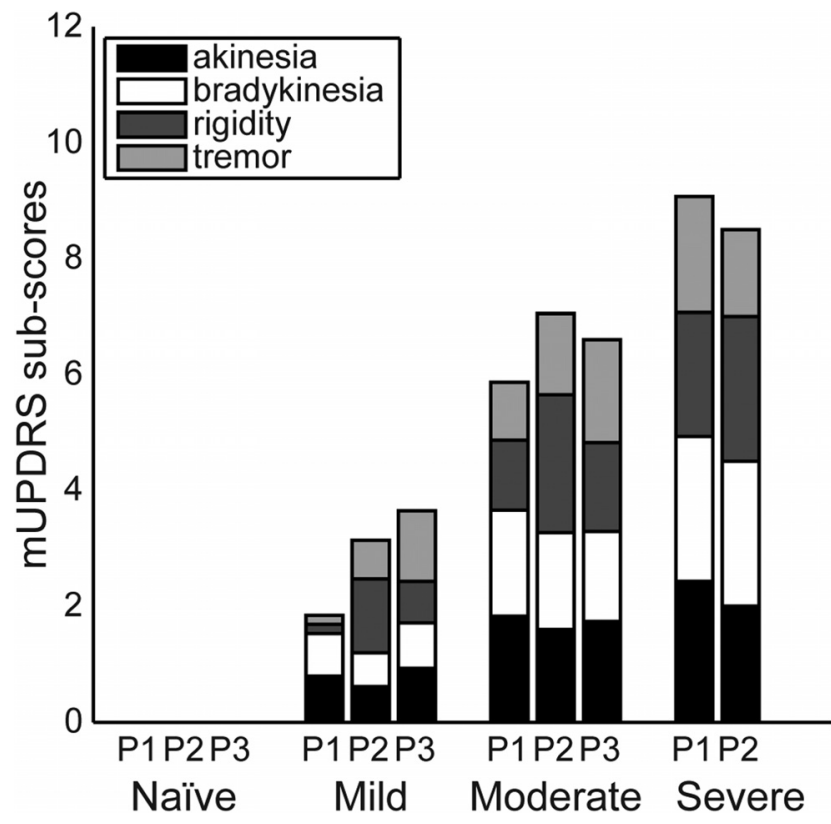

Figure 1. Progression of mUPDRS subscores for the cardinal parkinsonian motor signs in the three subjects (subjects P1, P2, and P3). Each subscore was rated on a scale of $0-3$, averaged over the contralateral arm and leg, and averaged over all days in the severity state (naive, mild, moderate, and severe).

\section{Results}

\section{Progressive model of Parkinson's disease}

A total of 676 LFPs was recorded across three subjects under naive, mild, moderate, and severe parkinsonian states (see Table 1). Parkinsonian motor signs increased progressively with MPTP treatment, but development of individual motor signs occurred at different rates across subjects (Figure 1). In the mild state, subjects P1 and P3 developed greater akinesia and bradykinesia, whereas rigidity was most prominent in subject P2. By the moderate parkinsonian state, subscores were more consistent across the three subjects, indicating a similar phenotypic expression of parkinsonism. Subject P3 was not carried through to the severe state due to confounding medical complications.

\section{Presence of pallidal beta oscillations in the naive state}

Before MPTP treatment, resting-state beta oscillations were observed throughout the globus pallidus in all three subjects (Fig. $2 A, B)$. Frequencies of this oscillatory activity spanned both low (11-22 Hz) and high $(22-32 \mathrm{~Hz})$ beta bands, with median 21.4 $\mathrm{Hz}$ in $\mathrm{P} 1$, median $18.7 \mathrm{~Hz}$ in $\mathrm{P} 2$, and median $24.7 \mathrm{~Hz}$ in $\mathrm{P} 3$. Significant oscillatory activity within the beta band was found to occur in $59 \%$ of recordings in $\mathrm{P} 1(n=61 / 103), 54 \%$ of recordings in P2 $(n=64 / 118)$, and $29 \%$ of recordings in P3 $(n=14 / 48$; Fig. $2 C)$. The distribution of frequencies of these beta oscillations was significantly different across subjects (Kruskal-Wallis, $p=1.45 \mathrm{e}-8$ ).

\section{Early shift in peak frequency of beta oscillations following MPTP treatment}

Beta oscillatory activity was also observed in the globus pallidus across all three levels of parkinsonian severity in each subject (Fig. $3 A-C)$. However, there was not a consistent trend between parkinsonian severity and the number of recordings containing resting-state beta oscillations. The percentages of recordings with beta oscillations across all states differed among the three subjects (Table 2), with P1 showing a tendency for increasing beta activity 


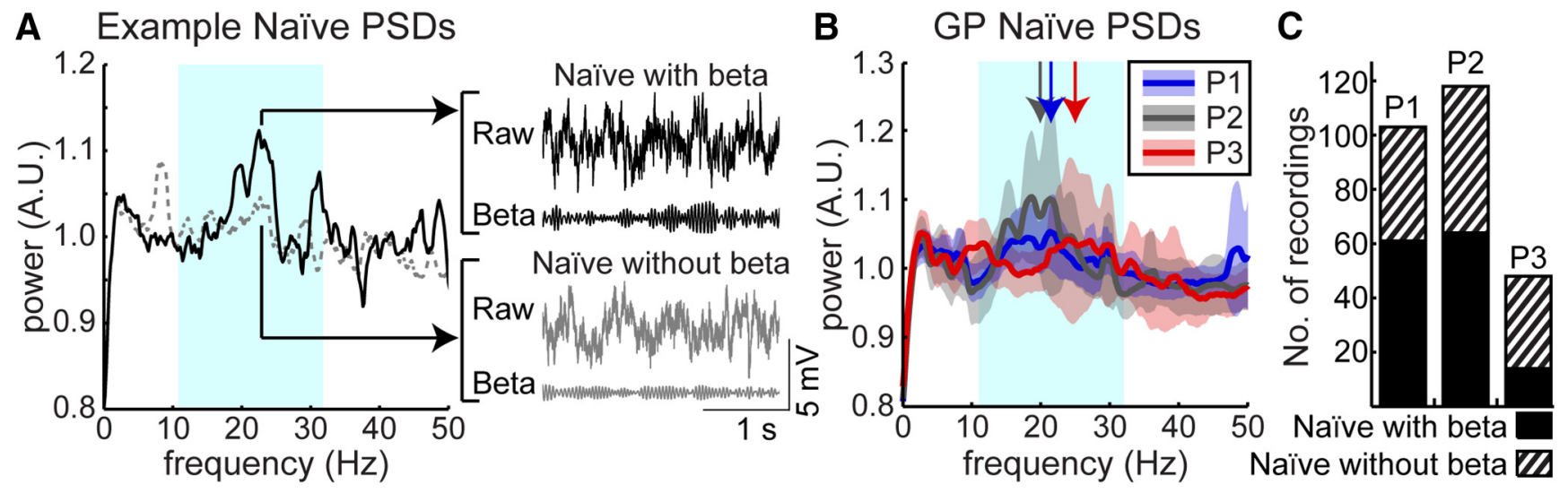

Figure 2. Beta oscillations in the naive state. $\boldsymbol{A}$, Example power spectra and time series data from the naive state identified with (solid black) and without (dashed gray) significant beta oscillatory activity. $\boldsymbol{B}$, Averaged power spectra across all recordings for each subject in the naive state. Bold lines show means and shaded areas show \pm 1 SD of flattened power spectra for subjects P1 (blue), P2 (gray), and P3 (red) in the GP in the naive state. Arrows demarcate median frequencies of beta oscillations for each subject. The cyan shaded area corresponds to the beta band. $\boldsymbol{C}$, Number of recordings with (solid) and without (hashed) detected beta peaks for each subject.

with severity, while P2 exhibited an increase from naive to mild and then a decrease from mild to moderate to severe. P3 also exhibited an increase from naive to mild followed by a large decrease from mild to moderate states. Further analysis using separate low- and high-frequency beta ranges also showed no clear relationship between parkinsonian severity and incidence of significant spectral power in the beta band.

Variability by state within a single subject could be obscured by lumping information into frequency bands instead of investigating the specific frequency at which individual oscillations occur. Therefore, the frequency distribution of significant beta oscillations within the power spectrum was compared across states (Fig. 3D-F). The nonparametric ANOVA revealed significant effects of disease state ( $p=1.31 \mathrm{e}-21)$, subject $(p=6.6 \mathrm{e}-14)$, and a significant interaction between state and subject $(p=2.06 \mathrm{e}-$ 11) on the frequency of oscillatory peaks within the beta band. Statistical differences between individual states were tested using the post hoc Dunn's all-pairs test with an adjusted significance level for multiple comparisons $(\alpha=0.5 / 6=8.333 \mathrm{e}-3)$. The broadness of the LFP beta oscillation that was seen in the naive state was caused by variability in the frequency at which the significant peaks occurred among the individual recordings. The median frequency of oscillations within the beta band also differed across states within the same subject, and differed between subjects. Oscillations in the naive state (red boxes; $\mathrm{P} 1$ interquartile range $17.9-22.6 \mathrm{~Hz}, \mathrm{P} 2$ range $16.0-21.4$ $\mathrm{Hz}$ ) were more broadly distributed compared with those observed in the severely parkinsonian state (black boxes; P1 interquartile range $14.3-17.5 \mathrm{~Hz}$, P2 range $11.9-14.6 \mathrm{~Hz}$ ).

In contrast to the lack of a consistent relationship to overall beta-band power, the median frequency of peaks within the beta band was found to shift with parkinsonian severity for all three subjects (Fig. 3D-F). In P1, beta oscillations were broadly distributed across the $11-32 \mathrm{~Hz}$ range in the naive state, with a median value at $21.4 \mathrm{~Hz}$. After induction of the mild parkinsonian state, the peak frequencies shifted toward the low beta range, centered around $15.6 \mathrm{~Hz}$ (Dunn's all-pairs test, $p=6.78 \mathrm{e}-7$ ). The oscillations persisted in the low beta range following the transition to the moderate (median $15.6 \mathrm{~Hz}$ ) and severe (median $15.5 \mathrm{~Hz}$ ) parkinsonian states. For P2, beta oscillations were similarly distributed across a broad range of low and high beta frequencies in the naive state (median $18.7 \mathrm{~Hz}$ ). Here, however, this distribution persisted into the mild state (median $21.5 \mathrm{~Hz}$ ), shifting toward the alpha and low beta bands only after transition to the moderate parkinsonian state (median $12.8 \mathrm{~Hz}, p=5.90 \mathrm{e}-15$ ) and continuing into the severe parkinsonian state (median $13.0 \mathrm{~Hz}$ ). P3 exhibited oscillatory activity in the pallidum that was isolated to the high beta range in the naive (median $24.7 \mathrm{~Hz}$ ) state. The median frequency of beta oscillations for $\mathrm{P} 3$ also decreased after induction of mild parkinsonism (median $21.9 \mathrm{~Hz}, p=4.75 \mathrm{e}-4$ ), and further decreased after transitioning to moderate parkinsonism (median $18.1 \mathrm{~Hz}$ ), consistent with the findings in P1 and P2.

\section{Effect of recording setup on beta oscillatory content}

The method of measuring bipolar LFPs constrained the source(s) of the signal to the region near both recording electrodes with intermicroelectrode distance of 1-5.347 mm for P1, 0.990-9.872 $\mathrm{mm}$ for P2, and 1.419-16.473 $\mathrm{mm}$ for P3. To ensure the change in the center frequency with state was not due to the measurement method, the correlation between frequency and distance was tested using Spearman's $\rho$. The test revealed no significant effect of 3D interelectrode tip distance on frequency of beta oscillations for P1 $(\rho=0.094, p=0.192)$, P2 $(\rho=-0.075, p=$ $0.371)$, or P3 $(\rho=-0.188, p=0.110)$. To verify that the observed changes in beta oscillatory activity (or lack thereof) were not a result of shorting oscillatory dipoles by the subtraction method, the Kruskal-Wallis nonparametric test and Dunn's all-pairs post hoc test were performed on the unipolar LFPs. As with the bipolar analysis, the unipolar analysis revealed significant effects of disease state (Kruskal-Wallis, $p=1.114 \mathrm{e}-7$ ) and subject $(p=$ $3.596 \mathrm{e}-17)$. Post hoc unipolar statistics were found to correspond with the results of the bipolar statistics, but bipolar statistics were more conservative. To test for intrinsic patterns in the frequency of beta oscillations with recording location, the discrete variables AP and ML coordinates were tested using Spearman's $\rho$, and the continuous variable DV coordinate was tested using nonparametric linear regression based on ranks. This analysis was performed on the unipolar data as the exact location of the source of the bipolar signal was not known. For P1 and P2, there was no significant effect of AP, ML, or DV on frequency of beta oscillations. For P3, there was no significant effect of ML or DV, but there was a significant correlation between AP and frequency of oscillation (Spearman's $\rho=0.4699, p=1.021 \mathrm{e}-4$ ). It should be noted, however, that only three different AP coordinates $(-1.5$ $\mathrm{mm},-0.5 \mathrm{~mm},+0.5 \mathrm{~mm}$ ) were used for naive recordings in P3, whereas 8-12 coordinates were used for $\mathrm{AP}$ and $\mathrm{ML}$ in all cases where no significance was found. 


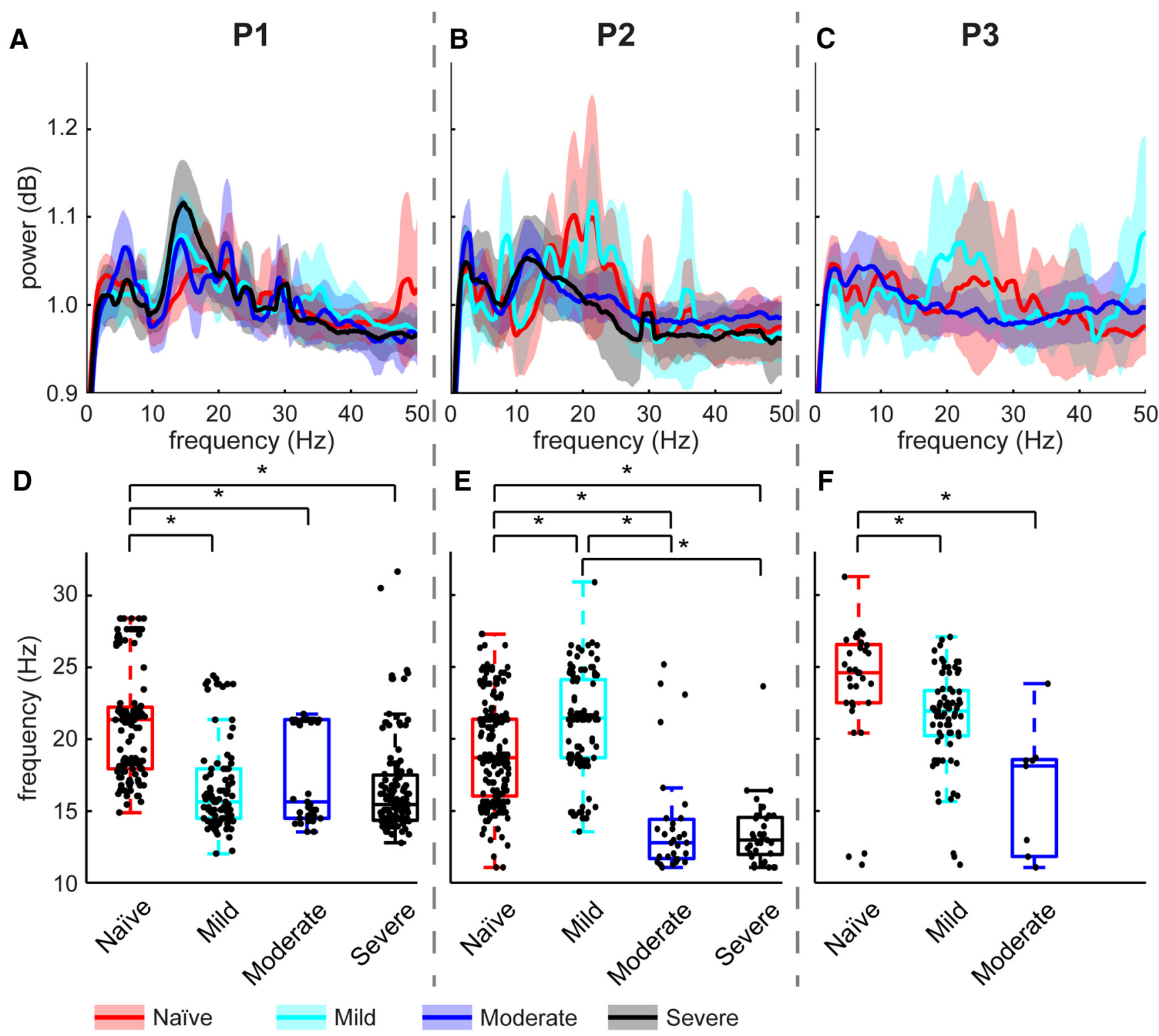

Figure 3. Evolution of beta oscillatory activity with increasing disease severity. A-C, Flattened PSDs of all recordings for subjects P1, P2, and P3. Bold traces signify means and shaded areas show $\pm 1 S D$. Red is naive, cyan is mild, blue is moderate, and black is severe. $\boldsymbol{D}-\boldsymbol{F}$, Peak beta frequencies recorded across all parkinsonian states. Dots represent frequencies in the beta range with peaks that exceeded the significance threshold. Dots are randomly distributed horizontally within each severity level for better visualization. Asterisks indicate significant differences, tested with Dunn's post hoc comparisons, and an adjusted significance level of $\alpha=8.333 \mathrm{e}-3$.

Table 2. Incidence of significant beta oscillations in LFP recordings across subjects and parkinsonian states

\begin{tabular}{lllll}
\hline & Naive & Mild & Moderate & Severe \\
\hline P1 & $59 \%$ & $61 \%$ & $69 \%$ & $84 \%$ \\
P2 & $54 \%$ & $77 \%$ & $42 \%$ & $35 \%$ \\
P3 & $29 \%$ & $59 \%$ & $7 \%$ & \\
\hline
\end{tabular}

Correlation analysis between LFP features and parkinsonian motor scores

Several features of oscillatory activity were tested for their relationship to each subject's overall parkinsonian motor severity score (mUPDRS). While some LFP features were significantly correlated with total mUPDRS, the trends were inconsistent and sometimes in the opposite direction across subjects (Fig. 4). For P1 and P2, the mUPDRS was significantly correlated with power in the beta bands, but the relationship was positive for P1 and negative for P2. All three subjects showed a negative correlation between the beta oscillatory frequency and mUPDRS, but this relationship was only significant for $\mathrm{P} 1$ and $\mathrm{P} 2$. The spectral power in the beta band defined by the mean oscillatory frequency in the moderate (P3) or severe (P1 and P2) state $\pm 4 \mathrm{~Hz}$ positively correlated with the mUPDRS in $\mathrm{P} 1(\rho=0.4925, p=2.699 \mathrm{e}-17)$ and $\mathrm{P} 2(\rho=0.5353, p=$ 5.206e-20) but negatively correlated with the mUPDRS for P3 ( $\rho=$ $-0.1962, p=0.0123$ ). Together, traditional spectral analysis did not identify features that could consistently predict the severity of the parkinsonian state in all three subjects.

Coupling of high-frequency oscillation amplitude to the phase of beta oscillations with increasing severity

A modulation index was investigated to measure the degree to which the amplitude of a particular frequency range was coupled to the phase of a lower frequency band, i.e., PAC. In the naive state, the amplitude of high-frequency oscillations (HFOs; 256- 


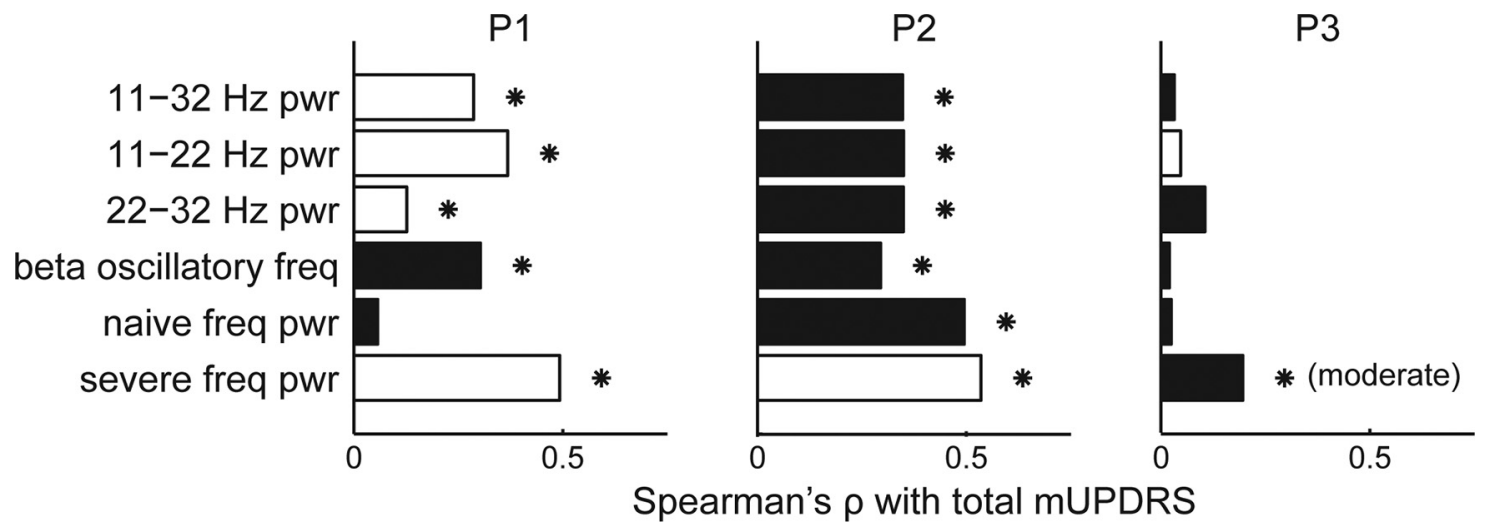

Figure 4. Correlation between LFP features and total mUPDRS. Bars indicate the magnitude of Spearman's $\rho$ correlation between specific beta features and total mUPDRS scores over all disease states grouped by individual subject (P1, P2, and P3). Features include the power (pwr) in the overall, low, and high beta bands; the frequency of beta oscillations (only for recordings with a significant beta oscillation); the power at the median frequency of beta oscillations over all naive recordings; and the power at the median frequency of beta oscillations over all severe recordings. White bars indicate positive correlations, black bars indicate negative correlations, and asterisks indicate significant correlations (Spearman's $\rho, \alpha=0.05$ ).

$362 \mathrm{~Hz}$ ) were significantly coupled to the phase of the gamma band $(45-64 \mathrm{~Hz})$ in $\sim 60 \%$ of the recordings in P1 (Fig. $5 A, B$ ). After the transition to the mild parkinsonian state, the frequency band of the driving phase broadened such that the HFO band became significantly coupled with the phases of both beta and gamma oscillations. With further increases in parkinsonian severity from moderate to severe, the coupling between beta phase and HFO amplitude became more prevalent. Specifically, there was a significant change in coupling between $11-16 \mathrm{~Hz}$ phase and the amplitude in the $181-256 \mathrm{~Hz}$ band $\left(\chi^{2}(3)=47.05, p=3.387 \mathrm{e}-10\right)$ and the 256-362 $\mathrm{Hz}$ band $\left(\chi^{2}(3)=52.54, p=\right.$ $2.292 \mathrm{e}-11)$ with parkinsonian state, measured by the Pearson's $\chi^{2}$ test (Fig. 5C). There was a significant change in PAC between $11-16 \mathrm{~Hz}$ phase and the amplitude in the $181-256 \mathrm{~Hz}$ band $\left(\chi^{2}(3)=24.11\right.$, $p=2.369 \mathrm{e}-5)$ and the $256-362 \mathrm{~Hz}$ band $\left(\chi^{2}(3)=31.58, p=6.412 \mathrm{e}-7\right)$ with parkinsonian severity in $\mathrm{P} 2$. There were no phase-amplitude pairs that significantly changed with parkinsonian severity in P3. While the percentage of recordings with HFO amplitude coupled to the phase of beta oscillations increased with parkinsonian severity in two subjects, the overall degree of coupling varied among subjects (Fig. 5C). In contrast, the gamma (45-64 $\mathrm{Hz}$ )-HFO coupling that was present in the naive state in all subjects was unchanged with parkinsonian severity $\left(\mathrm{P} 1 \chi^{2}(3)=\right.$ 1.487, $p=0.6853$; P2 $\chi^{2}(3)=2.133, \mathrm{p}$ 0.5453; P3 $\left.\chi^{2}(3)=0.488, p=0.9214\right)$.

In addition to the extent of phaseamplitude coupling, we also investigated the consistency with which the coupling occurred for a specific phase of both beta and gamma oscillations. For significantly
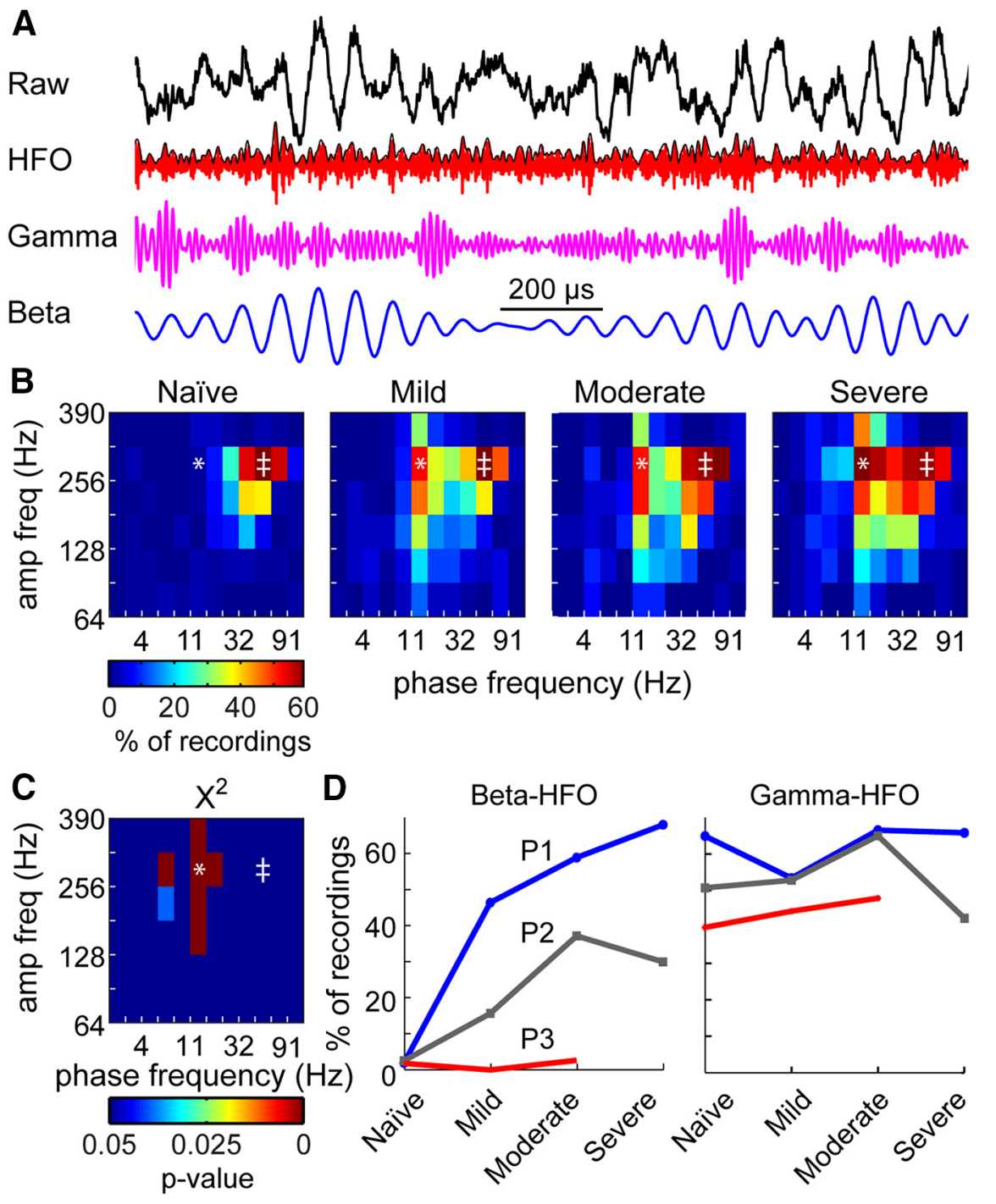

Figure 5. Progression of pallidal phase-amplitude coupling with parkinsonian severity. $A$, Example LFP time series with wideband $(0.1-390 \mathrm{~Hz})$, HF0-band $(256-362 \mathrm{~Hz})$, gamma-band $(45-64 \mathrm{~Hz})$, and beta-band $(11-16 \mathrm{~Hz})$ filtering. $\boldsymbol{B}$, Percentage of recordings with a significant $z$-score for each parkinsonian state in subject $P 1 . C, \chi^{2}$ results showing significant changes in the occurrence of coupling for each phase-amplitude pair in P1. D, Relationship between HF0 amplitude and beta (*) or gamma ( $¥)$ phases. All statistics used a significance level of $\alpha<0.05$ with a Bonferroni correction. 
coupled beta-HFO and gamma-HFO phase-amplitude pairs, the frequency at which the phase-amplitude distribution was maximal was measured across all recordings with significant $Z$-scores and plotted as a radial histogram (P1; Fig. $6 A-C)$. When the beta phase became coupled to the HFO amplitude in the mild state, the phase at which coupling occurred became highly variable across recordings and this persisted through the moderate and severe parkinsonian states (Fig. 6D). At the same time, while HFOs were significantly locked to the peak and trough of the gamma oscillations ( 0 and 180 degree phases) in the naive state, there was little change in mean phase direction of their coupling and angular dispersion from naive to the subsequent parkinsonian conditions (Fig. $6 D-E$ ). These data suggest that not only does HFO amplitude couple with a phase of beta oscillations as parkinsonian motor signs increase in severity, but the exact phase of coupling becomes spatially disordered throughout the pallidum.

\section{Discussion}

We investigated the evolution of pallidal LFP activity in a progressive NHP model of PD. The major findings include: (1) resting-state beta oscillations were present in the naive pallidum; (2) beta-band power increased, decreased, or did not change with MPTP, depending on the subject; (3) the median frequency of beta oscillations shifted to lower frequencies with increasing severity; (4) HFO amplitude was modulated by gamma-phase in the naive pallidum; and (5) coupling between beta-phase and HFO amplitude strengthened with increasing parkinsonian severity, while the phase at which coupling occurred became increasingly more variable.

\section{Significance of resting-state pallidal beta oscillations in the naive state}

The widespread spatial and temporal extent of naive-state beta oscillations in the globus pallidus challenges the basis for several theories and models of PD pathophysiology that assume beta oscillations emerge or are enhanced only following dopamine depletion and are indicative of the parkinsonian state (QuirogaVarela et al., 2013). While dopamine replacement therapy has been found to reduce beta activity in the STN of some patients (Kühn et al., 2006; Giannicola et al., 2010), there has been no direct confirmation that the underlying beta activity found in the drug-off state would not be present in a nondiseased human, with one study finding a negative correlation between parkinsonian severity and beta amplitude (Alavi et al., 2013). Given our observations of significant amounts of beta activity in the normal animal, the utility of beta band oscillations as a biomarker for PD motor signs should be re-examined. Indeed, it has been argued that beta activity is important for both normal motor and cognitive processes by promoting maintenance of the current motor or cognitive state, while its abnormal persistence leads to compromise in the ability to switch states (Engel and Fries, 2010).

The presence of beta oscillations in the naive-state globus pallidus could stem from multiple sources. In the naive state, beta oscillations exist in other parts of the motor network, including the striatum (Courtemanche et al., 2003; McCarthy et al., 2011; Leventhal et al., 2012) and motor cortex (Murthy and Fetz, 1992; Magill et al., 2004; Sharott et al., 2005; Mallet et al., 2008) of rodents and primates. This suggests that beta oscillatory activity in the globus pallidus could stem from propagation of similar spontaneous activity in the direct/indirect and/or hyperdirect pathways (Mallet et al., 2008; Kravitz et al., 2010). Afferents to the primate globus pallidus, including inhibitory inputs from the striatum as well as excitatory inputs from the STN, form a laminar structure throughout pallidum (Parent and Hazrati, 1995a, b), indicating that oscillatory activity within the basal gangliathalamo-cortical pathway could occur as a result of these afferent pathways (Plenz and Kital, 1999; Holgado et al., 2010; Buzsáki et al., 2012).

\section{Pallidal beta oscillations as a biomarker of parkinsonian severity}

Contrary to a previous MPTP NHP study investigating singleunit activity in globus pallidus (Leblois et al., 2007), we found no clear trend between the severity of parkinsonian motor signs and the proportion of LFP recordings with significant overall beta band activity. This discrepancy may be due to differences in the time over which the parkinsonian state developed, $30 \mathrm{~d}$ in Leblois et al. (2007), compared with months in ours, as well as mechanistic differences between oscillatory activity in spike and LFP data. Another study using serial injections of MPTP in NHPs found weak and inconsistent changes in spectral power in the cortex, STN, and GPi (Devergnas et al., 2014). In our study, a trend did emerge when examining the frequency (not amplitude) at which an oscillatory peak occurred within the beta band, instead of defining an arbitrary range over which activity was assumed to be homogenous. In the limited number of studies investigating pallidal LFPs in humans, GPi LFPs from PD patients showed beta activity that was centered between 18 and 26 (Priori et al., 2002), 11 and 30 (Brown et al., 2004), 13 and 30 (Kühn et al., 2008), and 11 and $30 \mathrm{~Hz}$ (Silberstein et al., 2003). Thus, the variability in clinical studies could stem, in part, from differences in defining the precise bounds of the spectral bands being assessed and from intersubject variation in peak oscillatory frequency.

The downward shift in peak frequency of beta oscillations was observed following MPTP treatment, and aligns with a model by Holgado et al., (2010) in which dopamine depletion reduced the effect of D2 receptors, causing the frequency of beta oscillations to decrease. Other factors may also be involved as oscillatory spiking in a mathematical model of striatum was found to shift after dopamine depletion (McCarthy et al., 2011). While the model prediction showed an increase (from 12 to $17 \mathrm{~Hz}$ ), which is inconsistent with the observed decrease in frequency in our study, the concept that resonant oscillatory frequencies in the basal ganglia change with dopamine depletion is consistent.

\section{Pallidal phase-amplitude coupling as a biomarker for parkinsonian severity}

Phase-amplitude coupling is an analytical technique that captures the extent to which oscillatory activity in one band becomes phase locked to oscillatory activity in another (Tort et al., 2008). Previous studies in PD patients have found significant relationships between beta band phase and gamma/HFO amplitude within the STN (Özkurt et al., 2011; Yang et al., 2014), within the motor cortex (de Hemptinne et al., 2013), and between the STN and motor cortex (Shimamoto et al., 2013). Our data show that this coupling is also present within the globus pallidus and that the driving frequency of the phase component of coupling changes with induction of a parkinsonian state. López-Ascarate et al. (2010) showed that the center frequencies of the beta and HFO bands in the STN were decreased in the off-dopaminergic medication state compared with the on-drug state. These results agree with our finding that the frequency of the driving phase broadened to include beta when transitioning from the naive to the parkinsonian condition. 
A

苋

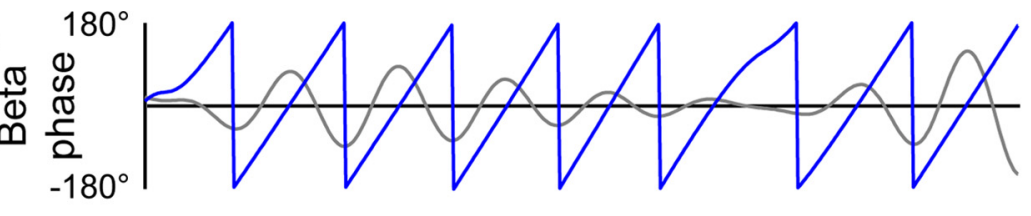

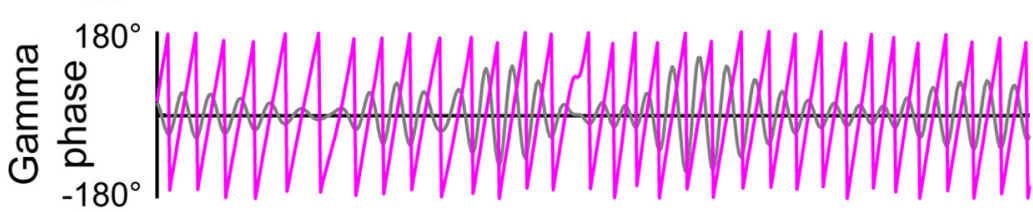

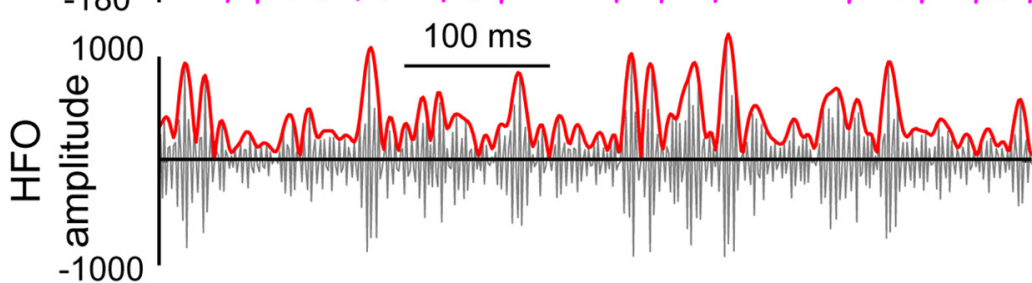

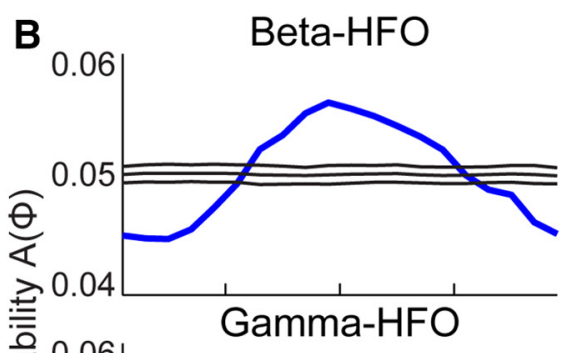

C

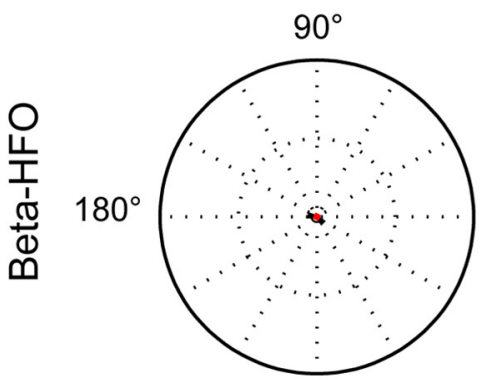

Naïve

Mild
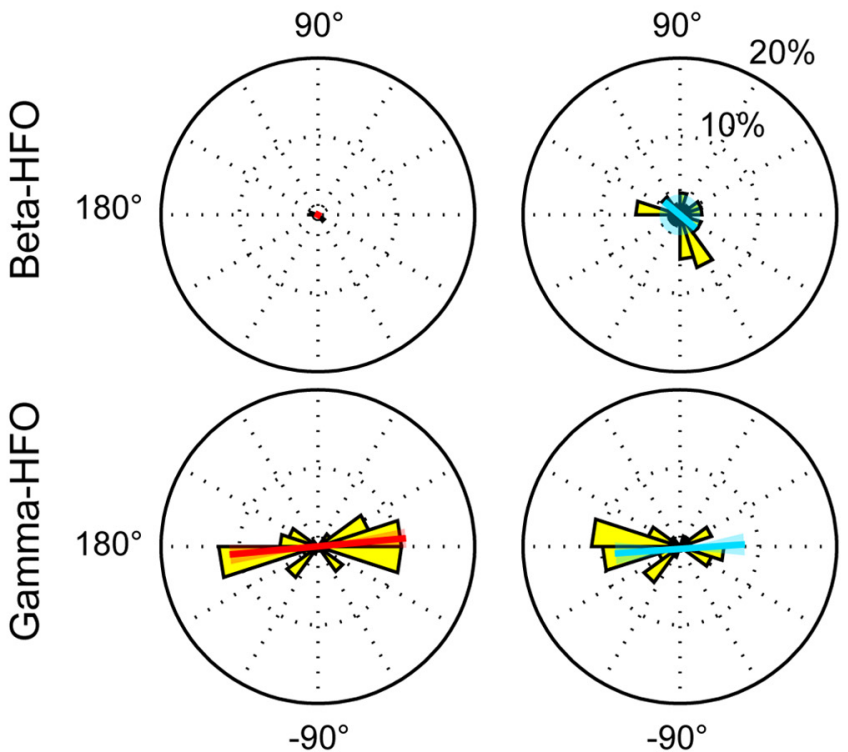

Moderate
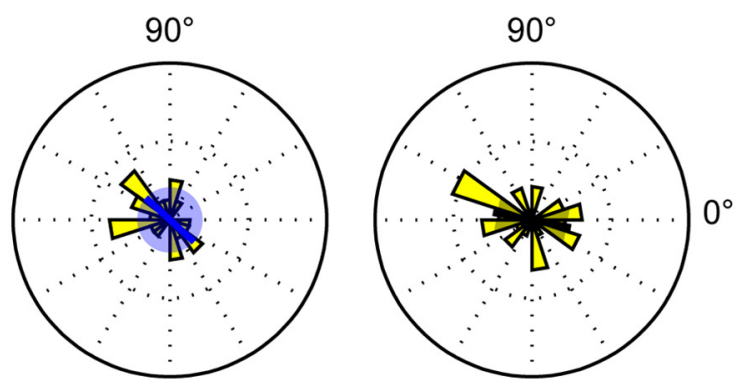

D
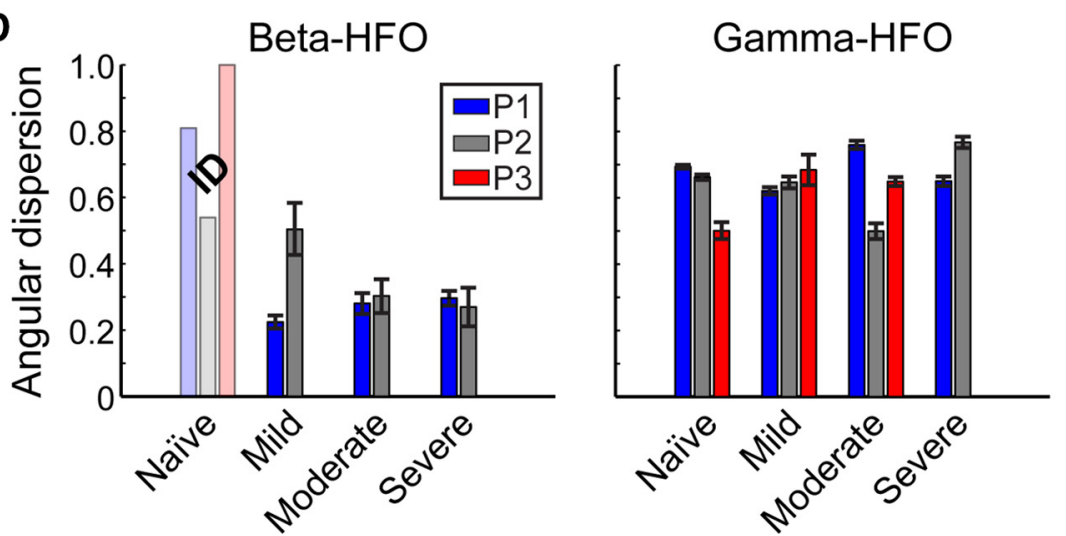

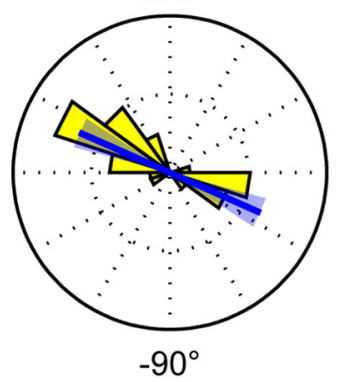

E

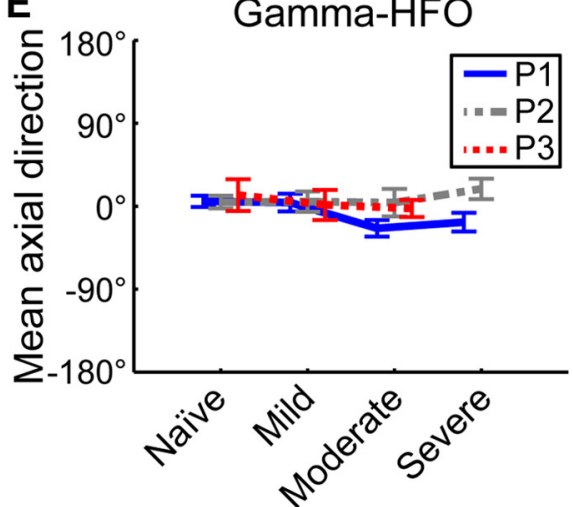

Figure 6. Differences in the locking of HFO amplitude to phases of beta and gamma oscillations for subject P1. $A$, Examples of beta (11-16 Hz, blue) and gamma (45-64 Hz, magenta) phase signals with simultaneous HFO (256-362 Hz, red) amplitude signal from an LFP in the severe state. Bandpass filtered data are shown in gray. $\boldsymbol{B}$, Coupling was measured by comparing the phase-amplitude distribution (bold line) with a distribution of time-shuffled surrogates (mean \pm 2 SD, shown with thin lines) for beta-HFO (top, blue) and gamma-HFO (magenta, bottom) pairs. $C$, In subject P1, radial histograms of the phase at which the phase-amplitude distribution in B was peaked for recordings with significant PAC $z$-scores (yellow). Beta was defined as 11-16 Hz, gamma as 45-64 Hz, and HF0 as 256 -362 Hz for all recordings. The bold colored line shows the mean axial direction with the shaded area representing the $95 \%$ confidence interval. For beta-HFO mild and moderate states, there was no significant axial direction as tested by the Omnibus test, so the $95 \%$ confidence interval encompasses the entire circle. $D$, Angular dispersion ( 0 represents dispersed angles, 1 represents aligned angles) and jackknife error bars of the radial distributions shown in C for all subjects and all parkinsonian states (P1, blue; P2, gray; P3, red). For all subjects, there were not enough recordings ( $N<6$, insufficient data, marked ID) with a significant beta-HFO modulation index to perform the dispersion analysis in the naive state (and in the mild and moderate states in P3; faded bars). $\boldsymbol{E}$, Mean axial direction with $95 \%$ confidence interval for all subjects and parkinsonian states for gamma-HFO coupling. Beta-HFO coupling is not shown because the distributions were not different from uniform, as tested by the Omnibus test. 
The consistency of the phase with respect to the PAC has been suggested to impact information transfer (Sauseng and Klimesch, 2008; Siegel et al., 2009). When the beta-HFO coupling became prevalent, the HFO was not coupled to a particular beta phase, suggesting that not only does coupling occur, but that the coupling is disordered. In contrast, the gamma-HFO coupling was present in the naive state and the amplitude of HFO was consistently high around the 0 and 180 degree phases of gamma even as parkinsonian severity progressed. This consistent phase locking could reflect a neural process necessary for proper coding of information that is disrupted when combined with aberrant coupling with beta oscillations. Consistent with our observations, Yang et al. (2014) also did not find a significant phase of locking between HFOs and beta phase across all LFP recordings, but did find significant locking between neuronal spiking and beta phase. Further investigation is necessary to determine how phase impacts the development and increasing severity in the cardinal motor signs of PD.

\section{Consistency of oscillatory biomarkers among subjects}

Of the three subjects, P1 most clearly supported the hypothesis that the spectral power of beta oscillations within the basal ganglia correlates with parkinsonian severity. To a degree, P2 also supported this hypothesis when the beta band was shifted to lower frequencies, but P3 contradicted it. In P3, there were very few LFPs containing significant beta oscillations in the moderate state. Such variability is also seen in the literature, with several reports showing elevated pathological beta activity in as few as 54\% (Rosa et al., 2011) and 77\% of patients (Özkurt et al., 2011). Inconsistency in neurophysiological signals between subjects is to be expected with the marked variability of motor signs that occur across individual PD patients, but a thorough understanding of the origin of these differences is necessary to identify a biomarker that could be used to diagnose and treat the disease as proposed in development of closed-loop deep brain stimulation systems. While all subjects developed a small amplitude postural tremor, the parkinsonian syndrome with rhesus macaques most resembled the akinetic-rigid subtype seen in human PD patients. Alternative animal models, such as the African green monkey, are known to develop prominent tremor and more resemble the tremor subtype of PD patients (Bergman et al., 1998). Therefore, the results of this study cannot directly inform the physiological differences underlying the tremor-dominant parkinsonian subtype.

The results of this study provide evidence that changing neural oscillations are a key factor in the progression of parkinsonism, but a pathological elevation of power in a predefined beta band in the globus pallidus does not serve as a biomarker of parkinsonism and dopamine depletion, as is believed to exist in the STN and motor cortex. Instead, decrease in the peak beta frequency occurred early in the transition from naive to mild and moderate parkinsonian states, while the degree to which the pallidal high-frequency oscillation amplitudes coupled to the phase of concurrent beta oscillations increased and was predictive of severity in the mild to moderate range in two of the three subjects. Neither of these biomarkers by themselves, however, were able to predict the transition from naive state to all three degrees of parkinsonian severity, generally failing to predict the transition from moderate to severe as defined in this study. Ultimately, there was variability in oscillatory changes across subjects, so a biomarker of parkinsonian condition will likely need to be tuned on a subject-specific basis and would need to incorporate multiple features of neuronal activity changes known to occur in the parkinsonian state. Alternatively, it is more likely that PD motor signs reflect a combination of changes across power spectrums, increases in some, decreases in others, with alterations in crossfrequency coupling that include amplitude and phase. Which changes are most important to the pathophysiology of PD and how they relate to the development of individual PD motor signs remains to be determined.

\section{References}

Alavi M, Dostrovsky JO, Hodaie M, Lozano AM, Hutchison WD (2013) Spatial extent of beta oscillatory activity in and between the subthalamic nucleus and substantia nigra pars reticulata of Parkinson's disease patients. Exp Neurol 245:60-71. CrossRef Medline

Bergman H, Wichmann T, Karmon B, DeLong MR (1994) The primate subthalamic nucleus. II. Neuronal activity in the MPTP model of parkinsonism. J Neurophysiol 72:507-520. Medline

Bergman H, Raz A, Feingold A, Nini A, Nelken I, Hansel D, Ben-Pazi H, Reches A (1998) Physiology of MPTP tremor. Mov Disord 13 [Suppl 3]:29-34. Medline

Berke JD, Okatan M, Skurski J, Eichenbaum HB (2004) Oscillatory entrainment of striatal neurons in freely moving rats. Neuron 43:883-896. CrossRef Medline

Bokil H, Andrews P, Kulkarni JE, Mehta S, Mitra PP (2010) Chronux: a platform for analyzing neural signals. J Neurosci Methods 192:146-151. CrossRef Medline

Boraud T, Bezard E, Bioulac B, Gross CE (2002) From single extracellular unit recording in experimental and human Parkinsonism to the development of a functional concept of the role played by the basal ganglia in motor control. Prog Neurobiol 66:265-283. CrossRef Medline

Brown P (2007) Abnormal oscillatory synchronisation in the motor system leads to impaired movement. Curr Opin Neurobiol 17:656-664. CrossRef Medline

Brown P, Mazzone P, Oliviero A, Altibrandi MG, Pilato F, Tonali PA, Di Lazzaro V (2004) Effects of stimulation of the subthalamic area on oscillatory pallidal activity in Parkinson's disease. Exp Neurol 188:480-490. CrossRef Medline

Buzsáki G, Anastassiou CA, Koch C (2012) The origin of extracellular fields and currents-EEG, ECoG, LFP and spikes. Nat Rev Neurosci 13:407-420. CrossRef Medline

Courtemanche R, Fujii N, Graybiel AM (2003) Synchronous, focally modulated beta-band oscillations characterize local field potential activity in the striatum of awake behaving monkeys. J Neurosci 23:11741-11752. Medline

de Hemptinne C, Ryapolova-Webb ES, Air EL, Garcia PA, Miller KJ, Ojemann JG, Ostrem JL, Galifianakis NB, Starr PA (2013) Exaggerated phase-amplitude coupling in the primary motor cortex in Parkinson disease. Proc Natl Acad Sci U S A 110:4780-4785. CrossRef Medline

de Solages C, Hill BC, Koop MM, Henderson JM, Bronte-Stewart H (2010) Bilateral symmetry and coherence of subthalamic nuclei beta band activity in Parkinson's disease. Exp Neurol 221:260-266. CrossRef Medline

Devergnas A, Pittard D, Bliwise D, Wichmann T (2014) Relationship between oscillatory activity in the cortico-basal ganglia network and parkinsonism in MPTPtreated monkeys. Neurobiol Dis 68:156-166. CrossRef Medline

Doyle LM, Kühn AA, Hariz M, Kupsch A, Schneider GH, Brown P (2005) Levodopa-induced modulation of subthalamic beta oscillations during self-paced movements in patients with Parkinson's disease. Eur J Neurosci 21:1403-1412. CrossRef Medline

Elder CM, Hashimoto T, Zhang J, Vitek JL (2005) Chronic implantation of deep brain stimulation leads in animal models of neurological disorders. J Neurosci Methods 142:11-16. CrossRef Medline

Engel AK, Fries P (2010) Beta-band oscillations-signalling the status quo? Curr Opin Neurobiol 20:156-165. CrossRef Medline

Filion M, Tremblay L (1991) Abnormal spontaneous activity of globus pallidus neurons in monkeys with MPTP-induced parkinsonism. Brain Res 547:142-151. CrossRef Medline

George JS, Strunk J, Mak-McCully R, Houser M, Poizner H, Aron AR (2013) Dopaminergic therapy in Parkinson's disease decreases cortical beta band coherence in the resting state and increases cortical beta band power during executive control. Neuroimage Clin 3:261-270. CrossRef Medline

Giannicola G, Marceglia S, Rossi L, Mrakic-Sposta S, Rampini P, Tamma F, Cogiamanian F, Barbieri S, Priori A (2010) The effects of levodopa and ongoing deep brain stimulation on subthalamic beta oscillations in Parkinson's disease. Exp Neurol 226:120-127. CrossRef Medline

Goldberg JA, Rokni U, Boraud T, Vaadia E, Bergman H (2004) Spike synchronization in the cortex/basal-ganglia networks of Parkinsonian pri- 
mates reflects global dynamics of the local field potentials. J Neurosci 24:6003-6010. CrossRef Medline

Hahn PJ, McIntyre CC (2010) Modeling shifts in the rate and pattern of subthalamopallidal network activity during deep brain stimulation. J Comput Neurosci 28:425-441. CrossRef Medline

Holgado AJ, Terry JR, Bogacz R (2010) Conditions for the Generation of Beta Oscillations in the Subthalamic Nucleus-Globus Pallidus Network. J Neurosci 30:12340-12352. CrossRef Medline

Jensen O, Goel P, Kopell N, Pohja M, Hari R, Ermentrout B (2005) On the human sensorimotor-cortex beta rhythm: sources and modeling. Neuroimage 26:347-355. CrossRef Medline

Kravitz AV, Freeze BS, Parker PR, Kay K, Thwin MT, Deisseroth K, Kreitzer AC (2010) Regulation of parkinsonian motor behaviours by optogenetic control of basal ganglia circuitry. Nature 466:622-626. CrossRef Medline

Kühn AA, Trottenberg T, Kivi A, Kupsch A, Schneider GH, Brown P (2005) The relationship between local field potential and neuronal discharge in the subthalamic nucleus of patients with Parkinson's disease. Exp Neurol 194:212-220. CrossRef Medline

Kühn AA, Kupsch A, Schneider GH, Brown P (2006) Reduction in subthalamic $8-35 \mathrm{~Hz}$ oscillatory activity correlates with clinical improvement in Parkinson's disease. Eur J Neurosci 23:1956-1960. CrossRef Medline

Kühn AA, Kempf F, Brücke C, Gaynor Doyle L, Martinez-Torres I, Pogosyan A, Trottenberg T, Kupsch A, Schneider GH, Hariz MI, Vandenberghe W, Nuttin B, Brown P (2008) High-frequency stimulation of the subthalamic nucleus suppresses oscillatory beta activity in patients with Parkinson's disease in parallel with improvement in motor performance. J Neurosci 28:6165-6173. CrossRef Medline

Kühn AA, Tsui A, Aziz T, Ray N, Brücke C, Kupsch A, Schneider GH, Brown P (2009) Pathological synchronisation in the subthalamic nucleus of patients with Parkinson's disease relates to both bradykinesia and rigidity. Exp Neurol 215:380-387. CrossRef Medline

Leblois A, Meissner W, Bioulac B, Gross CE, Hansel D, Boraud T (2007) Late emergence of synchronized oscillatory activity in the pallidum during progressive Parkinsonism. Eur J Neurosci 26:1701-1713. CrossRef Medline

Leventhal DK, Gage GJ, Schmidt R, Pettibone JR, Case AC, Berke JD (2012) Basal ganglia beta oscillations accompany cue utilization. Neuron 73:523536. CrossRef Medline

López-Azcarate J, Tainta M, Rodríguez-Oroz MC, Valencia M, González R, Guridi J, Iriarte J, Obeso JA, Artieda J, Alegre M (2010) Coupling between beta and high-frequency activity in the human subthalamic nucleus may be a pathophysiological mechanism in Parkinson's disease. J Neurosci 30:6667-6677. CrossRef Medline

Magill PJ, Sharott A, Bolam JP, Brown P (2004) Brain state-dependency of coherent oscillatory activity in the cerebral cortex and basal ganglia of the rat. J Neurophysiol 92:2122-2136. CrossRef Medline

Mallet N, Pogosyan A, Sharott A, Csicsvari J, Bolam JP, Brown P, Magill PJ (2008) Disrupted dopamine transmission and the emergence of exaggerated beta oscillations in subthalamic nucleus and cerebral cortex. J Neurosci 28:4795-4806. CrossRef Medline

McCarthy MM, Moore-Kochlacs C, Gu X, Boyden ES, Han X, Kopell N (2011) Striatal origin of the pathologic beta oscillations in Parkinson's disease. Proc Natl Acad Sci U S A 108:11620-11625. CrossRef Medline

Milstein J, Mormann F, Fried I, Koch C (2009) Neuronal shot noise and Brownian 1/f2 behavior in the local field potential. PLoS One 4:e4338. CrossRef Medline

Miocinovic S, Zhang J, Xu W, Russo GS, Vitek JL, McIntyre CC (2007) Stereotactic neurosurgical planning, recording, and visualization for deep brain stimulation in non-human primates. J Neurosci Methods 162:3241. CrossRef Medline

Murthy VN, Fetz EE (1992) Coherent 25- to 35-Hz oscillations in the sensorimotor cortex of awake behaving monkeys. Proc Natl Acad Sci U S A 89:5670-5674. CrossRef Medline

Murthy VN, Fetz EE (1996) Oscillatory activity in sensorimotor cortex of awake monkeys: synchronization of local field potentials and relation to behavior. J Neurophysiol 76:3949-3967. Medline

Özkurt TE, Butz M, Homburger M, Elben S, Vesper J, Wojtecki L, Schnitzler A (2011) High frequency oscillations in the subthalamic nucleus: a neurophysiological marker of the motor state in Parkinson's disease. Exp Neurol 229:324-331. CrossRef Medline

Parent A, Hazrati LN (1995a) Functional anatomy of the basal ganglia I. The cortico-basal ganglia-thalamo-cortical loop. Brain Res Rev 20:91-127. CrossRef Medline
Parent A, Hazrati LN (1995b) Functional anatomy of the basal ganglia. II. The place of subthalamic nucleus and external pallidum in basal ganglia circuitry. Brain Res Brain Res Rev 20:128-154. CrossRef Medline

Plenz D, Kital ST (1999) A basal ganglia pacemaker formed by the subthalamic nucleus and external globus pallidus. Nature 400:677-682. CrossRef Medline

Priori A, Foffani G, Pesenti A, Bianchi A, Chiesa V, Baselli G, Caputo E, Tamma F, Rampini P, Egidi M, Locatelli M, Barbieri S, Scarlato G (2002) Movement-related modulation of neural activity in human basal ganglia and its L-DOPA dependency: recordings from deep brain stimulation electrodes in patients with Parkinson's disease. Neurol Sci 23 [Suppl 2]: S101-S102. CrossRef Medline

Quiroga-Varela A, Walters JR, Brazhnik E, Marin C, Obeso JA (2013) What basal ganglia changes underlie the parkinsonian state? The significance of neuronal oscillatory activity. Neurobiol Dis 58:242-248. CrossRef Medline

Ray NJ, Jenkinson N, Wang S, Holland P, Brittain JS, Joint C, Stein JF, Aziz T (2008) Local field potential beta activity in the subthalamic nucleus of patients with Parkinson's disease is associated with improvements in bradykinesia after dopamine and deep brain stimulation. Exp Neurol 213: 108-113. CrossRef Medline

Rosa M, Giannicola G, Servello D, Marceglia S, Pacchetti C, Porta M, Sassi M, Scelzo E, Barbieri S, Priori A (2011) Subthalamic local field beta oscillations during ongoing deep brain stimulation in Parkinson's disease in hyperacute and chronic phases. Neurosignals 19:151-162. CrossRef Medline

Sanes JN, Donoghue JP (1993) Oscillations in local field potentials of the primate motor cortex during voluntary movement. Proc Natl Acad Sci U S A 90:4470-4474. CrossRef Medline

Sauseng P, Klimesch W (2008) What does phase information of oscillatory brain activity tell us about cognitive processes? Neurosci Biobehav Rev 32:1001-1013. CrossRef Medline

Sharott A, Magill PJ, Bolam JP, Brown P (2005) Directional analysis of coherent oscillatory field potentials in the cerebral cortex and basal ganglia of the rat. J Physiol 562:951-963. CrossRef Medline

Shimamoto SA, Ryapolova-Webb ES, Ostrem JL, Galifianakis NB, Miller KJ, Starr PA (2013) Subthalamic nucleus neurons are synchronized to primary motor cortex local field potentials in Parkinson's disease. J Neurosci 33:7220-7233. CrossRef Medline

Siegel M, Warden MR, Miller EK (2009) Phase-dependent neuronal coding of objects in short-term memory. Proc Natl Acad Sci U S A 106:2134121346. CrossRef Medline

Silberstein P, Kühn AA, Kupsch A, Trottenberg T, Krauss JK, Wöhrle JC, Mazzone P, Insola A, Di Lazzaro V, Oliviero A, Aziz T, Brown P (2003) Patterning of globus pallidus local field potentials differs between Parkinson's disease and dystonia. Brain 126:2597-2608. CrossRef Medline

Tort AB, Kramer MA, Thorn C, Gibson DJ, Kubota Y, Graybiel AM, Kopell NJ (2008) Dynamic cross-frequency couplings of local field potential oscillations in rat striatum and hippocampus during performance of a T-maze task. Proc Natl Acad Sci U S A 105:20517-20522. CrossRef Medline

Tort AB, Komorowski R, Eichenbaum H, Kopell N (2010) Measuring phase-amplitude coupling between neuronal oscillations of different frequencies. J Neurophysiol 104:1195-1210. CrossRef Medline

Vitek JL, Zhang J, Hashimoto T, Russo GS, Baker KB (2012) External pallidal stimulation improves parkinsonian motor signs and modulates neuronal activity throughout the basal ganglia thalamic network. Exp Neurol 233:581-586. CrossRef Medline

Weinberger M, Mahant N, Hutchison WD, Lozano AM, Moro E, Hodaie M, Lang AE, Dostrovsky JO (2006) Beta oscillatory activity in the subthalamic nucleus and its relation to dopaminergic response in Parkinson's disease. J Neurophysiol 96:3248-3256. CrossRef Medline

Whitmer D, de Solages C, Hill B, Yu H, Henderson JM, Bronte-Stewart H (2012) High frequency deep brain stimulation attenuates subthalamic and cortical rhythms in Parkinson's disease. Front Hum Neurosci 6:155. CrossRef Medline

Wichmann T, DeLong MR (2003) Pathophysiology of Parkinson's disease: the MPTP primate model of the human disorder. Ann N Y Acad Sci 991:199-213. CrossRef Medline

Yang AI, Vanegas N, Lungu C, Zaghloul KA (2014) Beta-coupled highfrequency activity and Beta-locked neuronal spiking in the subthalamic nucleus of Parkinson's disease. J Neurosci 34:12816-12827. CrossRef Medline

Zaidel A, Spivak A, Grieb B, Bergman H, Israel Z (2010) Subthalamic span of beta oscillations predicts deep brain stimulation efficacy for patients with Parkinson's disease. Brain 133:2007-2021. CrossRef Medline 